\title{
The Protective Effect of Catechin and Rutin on Cigarette Smoke Extract- induced Injury in Irradiated Rats
}

\author{
Mona A. El-Ghazaly ${ }^{1 *}$, Aliaa H. Ashoub ${ }^{1}$, Nour El-Din A. Mohamed ${ }^{1}$ and Sanaa A. \\ Kenawy $^{2}$ \\ ${ }^{1}$ Drug Radiation Research Department, National Centre for Radiation Research and \\ Technology, Atomic Energy Authority, and 2Pharmacology and Toxicology Department, \\ Faculty of Pharmacy, Cairo University, Cairo, Egypt
}

\begin{abstract}
THE present study was designed to investigate the possible protective effects of catechin and rutin and their possible mechanisms of action in guarding against the oxidative stress and inflammation induced by ionizing radiation and/ or cigarette smoke extract in rats. Exposure of rats to acute doses of $\gamma$-radiation or administration of cigarette smoke extract (CSE) in this study were found to exert an oxidative stress due to generation of ROS, which are characterized by elevation in MDA and nitric oxide levels and depletion in reduced glutathione, as well as elevation in MPO activity and level of TNF- $\alpha$. The results also showed that activities of ALT, AST, ALP, and LDH were increased. Damaging effects were significantly increased in animals exposed to gamma radiation combined with administration of cigarette smoke extract in comparison to either irradiation or administration of cigarette smoke extract. Pretreatment with catechin or rutin largely protected against the change in all the measured parameters. Conclusion: Catechin and rutin might have the potential to modulate the damage induced by radiation exposure in cigarette smoke-treated animals
\end{abstract}

Keywords : $\gamma$-radiation, Cigarette smoke extract, Catechin, rutin, Oxidative stress.

\section{INTRODUCTION}

Ionizing radiations (IR) are widely used in treating cancers of various tissues where it is used to kill or arrest the growth of tumor cells (Meister, 2005). The gastrointestinal (GI) tract is among the most radiosensitive organ systems in the body. In addition to the intestinal epithelium crypt, radiation exposure damages supporting structures such as endocrine glands of the GI tract (HauerJensen et al., 2007).

It is well established that cigarette smoking can increase the risk of chronic obstructive pulmonary diseases, cardiovascular diseases and several forms of cancer, in particular, cancers of lung, oropharynx, larynx and esophagus (Tsiara et al., 2003). Also, cigarette smoking increases both the incidence and relapse rate of peptic ulcer diseases and delays ulcer healing (Ma et al., 1999).

Catechin is a polyphenolic flavonoid present in green tea, black tea and other plant foods (Cook and Samman, 1996). Catechins are strong antioxidants and free radical quenchers (Babu and Liu, 2008).

Rutin, is a natural flavone derivative, which is known for its anti-inflammatory and vasoactive properties (Lindahl and Tagesson, 1997). It has been reported that rutin prevents gastric mucosal ulceration in animal models (Pérez-Guerrero et al., 1994) and has also been found to be a strong scavenger of hydroxyl and superoxide radicals (Metodiewa et al., 1997).

The present study was designed to investigate the possible protective effects of catechin and rutin and their possible mechanisms of action in guarding against the oxidative stress and inflammation induced by IR and/or CSE in rats.

Corresponding author : Email: monaghazaly@gmail.com 


\section{MATERIALS AND METHODS}

Animals

Male albino Wistar rats, each weighing 120$180 \mathrm{~g}$, were purchased from the animal breeding unit of National Research Centre, Giza, Egypt. The rats were allowed free access to water ad libitum and were fed a standard pellet diet. They were housed for at least one week before starting the experiment.

\section{Chemicals}

Cleopatra ${ }^{\circledR}$ Super Star cigarettes (Eastern Company, Giza, Egypt) were used in this study. $(+)$ Catechin (Fluka, St.Gallen, Switzerland) and Rutin (Sigma, St.Louis, Mo, USA). The kits used were: Alanine transaminase, aspartate transaminase, alkaline phosphatase, and nitric oxide colorimetric kits (Biodiagnostic, Giza, Egypt). Lactate dehydrogenase kinetic kit (Biomed, Cairo, Egypt). TNF- $\alpha$ (tumor necrosis factor- $\alpha$ ) ELISA kit (R\&D Systems, MN, USA). All other biochemical reagents were of pure analytical grade.

\section{Irradiation of Animals}

Whole body $\gamma$-irradiation of rats was carried out at the National Centre for Radiation Research and Technology (NCRRT), Atomic Energy Authority, Egypt, using the Gamma Cell-40 biological irradiator with a Caesium 137 source manufactured by the Atomic Energy of Canada Limited (AECL). Animals were exposed to acute dose level of $2 \mathrm{~Gy}$ delivered at a rate of $0.72 \mathrm{~Gy} / \mathrm{min}$.

\section{Preparation of Cigarette Smoke Extracts}

CSEs were prepared according to the method of Ma, et al., (2000). The substances in this cigarette smoke were extracted using a smoke perfusion system using chloroform and 95\% ethanol respectively. The substances in the smoke were thus absorbed in the solvents. The substances dissolved in ethanol were regarded as ethanol fraction. This fraction was preconcentrated by a rotary evaporator (Rotavapor Buchi-RE111, Flawil, Switzerland) to evaporate the excess ethanol. Then, chloroform was added to the ethanol fraction to extract those substances soluble in chloroform. The remaining insoluble part was regarded as ethanol extract (ECE). All the chloroform soluble fractions were combined and concentrated again following the same procedures, and this was known as chloroform extract (CCE).Both ECE and CCE were finally prepared in $0.1 \%$ dimethyl sulfoxide (DMSO) solution before oral administration (Shin et al., 2002).

\section{Experimental Design}

Animals were randomly classified into six experimental groups, eight rats each. The first group received saline and served as normal group. The second group was exposed to a single dose of whole body $\gamma$ - rays at dose level of $2.0 \mathrm{~Gy}$. Third group received CSE at a dose of $5 \mathrm{mg} / \mathrm{kg}$ p.o for 3 successive days. The fourth group received CSE at a dose of $5 \mathrm{mg} / \mathrm{kg}$ p.o for 3 successive days then exposed to radiation. The fifth group received catechin at a dose of $50 \mathrm{mg} / \mathrm{kg}$ p.o.(Rao and Vijayakumar, 2007) and CSE at a dose of 5 $\mathrm{mg} / \mathrm{kg}$ p.o for 3 successive irradiations. The last group received rutin at a dose of $40 \mathrm{mg} / \mathrm{kg}$ p.o for 10 successive days (Florek et al., 2005), and CSE at a dose of $5 \mathrm{mg} / \mathrm{kg}$ p.o for 3 successive days starting from day 8 of rutin injection. After the last dose of rutin and CSE, animals were exposed to radiation.

\section{Blood Samples}

Rats were sacrificed after $24 \mathrm{hr}$ of radiation exposure and blood samples were collected in a dry clean test tube. $0.1 \mathrm{ml}$ was added to a dry clean test tube containing heparin for the estimation of glutathione. The rest of blood was incubated at $37^{\circ} \mathrm{C}$ for $20 \mathrm{~min}$ then centrifuged at $3000 \mathrm{rpm}$ for $15 \mathrm{~min}$. to separate serum to be used for determination of malondialdehyde (MDA), nitric oxide (NO), and tumor necrosis factor- $\alpha$ (TNF- $\alpha$ ) levels and the activity of alanine transaminase (ALT), and aspartate transaminase (AST), alkaline phosphatase (ALP), and lactate dehydrogenase (LDH).

\section{Tissue Samples}

The stomach was excised, opened along the greater curvature, and rinsed thoroughly with normal saline. After the stomach was blotted dry the glandular mucosa was scraped with a glass slide on an ice-cold dish. The mucosal samples were stored at $-20^{\circ} \mathrm{C}$ until evaluation of myeloperoxidase (MPO) activity.

\section{Biochemical Analysis}

Estimation of ALT, AST, ALP, NO, LDH, and TNF- $\alpha$ in Serum

The biochemical estimation of ALT, AST, and ALP activities and NO level was assayed using 
colorimetric kits according to the manufacturers' instructions. ALT and AST were assayed using the method of Reitman and Frankel (1957). ALP and NO were assayed according to the methods of Belfield and Goldberg (1971) and Montgomery and Dymock (1961), respectively. LDH activity was determined kinetically using a commercial kit according to the method of Gay et al., (1968). TNF- $\alpha$ level was determined using ELISA kit according to the method of Flick and Gifford, (1984).

\section{Estimation of MDA and GSH Levels}

MDA was measured as an end product of lipid peroxidation according to the method of Uchiyama and Mihara (1978). GSH level was chemically determined using 5,5'-dithionitrobenzoic acid according to the method of Beutler et al., (1963).

\section{Estimation of MPO Activity}

Myeloperoxidase activity in gastric mucosa was chemically determined according to the method of Shin et al. (2002).

\section{Statistical Analysis:}

Values are given as means \pm SEM. Comparisons between different groups were carried out by one way analysis of variance (ANOVA) followed by Tukey-Kramer's multiple comparison test. The differences were considered statistically significant at $\mathrm{p} \leq 0.05$.

\section{RESULTS}

Effects of catechin or rutin treatment on serum ALT, AST, \&ALP activities in whole body $\gamma$ irradiated and CSE treated rats

As illustrated in Fig. 1, whole body $\gamma$-irradiation or CSE administration induced a significant rise in serum ALT, AST and ALP activities compared to normal values. On the other hand, administration of CSE followed by whole body $\gamma$-irradiation resulted in a more increment in these enzymes activities. Irradiated animals exposed to CSE and pretreatment with catechin and rutin attenuated the rise in ALT, AST and ALP activities.

Effects of catechin or rutin treatment on serum levels of MDA, NO and blood GSH in whole body $\gamma$-irradiated and CSE treated rats

Data shown in Table 1 indicate that whole body $\gamma$-irradiation or CSE administration resulted in a significant decrease of GSH blood level and a significant increase in serum MDA and NO
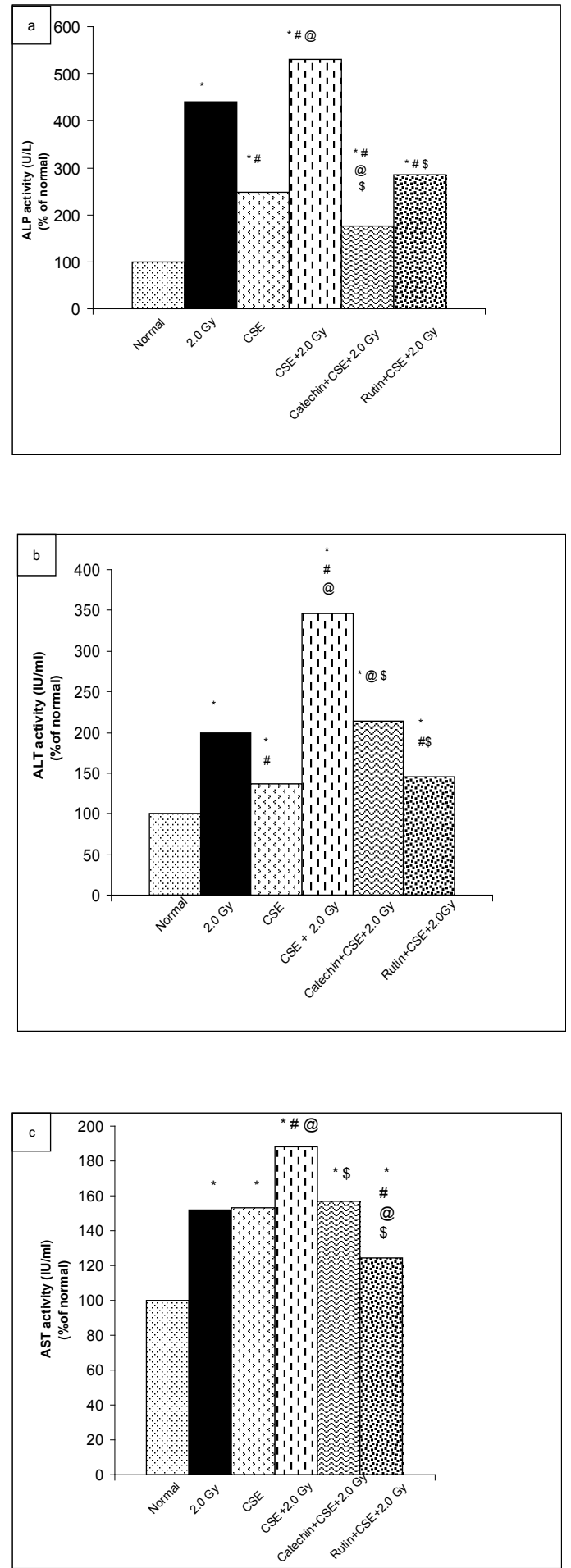

Fig. 1. Effect of catechin $(50 \mathrm{mg} / \mathrm{kg})$ or rutin $(40 \mathrm{mg} / \mathrm{kg})$ on serum activity of (a) alkaline phosphatase, (b) alanine transaminase (ALT) and (c) aspartate transaminase in CSE treated and gamma irradiated rats.

.All values are expressed as \% mean .significantly different from normal at $\mathrm{p}<0.05$ :* significantly different from 2 Gy at $\mathrm{p}<0.05$ :\# .significantly different from CSE at $\mathrm{p}<0.05:$ @ significantly different from CSE +2 Gy at $\mathrm{p}<0.05: \$$

Egypt.J.'Rad. Sci. Applic. 39, No.1 (2017) 
levels compared to normal values. On the other hand, administration of CSE followed by whole body $\gamma$-irradiation resulted in a more decrease in GSH level and more increase in MDA and NO levels. Catechin or rutin treatment before whole body $\gamma$-radiation and CSE administration resulted in a slight increase in GSH level and a significant decrease in MDA and NO levels.

TABLE 1 . Effects of catechin $(50 \mathrm{mg} / \mathrm{kg})$ or rutin $(40 \mathrm{mg} / \mathrm{kg})$ on malondialdehyde (MDA), nitric oxide (NO) serum levels and glutathione (GSH) blood level in whole body gamma irradiated rats $(2$ Gy) pretreated with $\mathrm{CSE}(5 \mathrm{mg} / \mathrm{kg})$.

\begin{tabular}{|c|c|c|c|}
\hline $\begin{array}{l}\text { Parameters } \\
\text { Groups }\end{array}$ & $\begin{array}{c}\text { MDA } \\
(\mathrm{nmol} / \mathrm{ml})\end{array}$ & $\begin{array}{c}\text { GSH } \\
(\mathrm{mg} / \mathrm{ml})\end{array}$ & $\begin{array}{c}\text { NO } \\
(\mu \mathrm{mol} / \mathrm{L})\end{array}$ \\
\hline Normal (saline) & $\begin{array}{c}3.52 \pm \\
0.59\end{array}$ & $\begin{array}{c}12.84 \pm \\
0.71\end{array}$ & $\begin{array}{c}2.68 \pm \\
0.06\end{array}$ \\
\hline $\begin{array}{l}\gamma \text {-radiation } 2.0 \\
\text { Gy }\end{array}$ & $\begin{array}{c}8.55 \pm \\
0.19\end{array}$ & $\begin{array}{c}4.65 \pm \\
0.28\end{array}$ & $\begin{array}{c}* \\
5.99 \pm \\
0.31\end{array}$ \\
\hline CSE (5mg/kg) & $\begin{array}{c}* \# \\
5.57 \pm \\
0.13 \\
\end{array}$ & $\begin{array}{c}5.41 \pm \\
0.39\end{array}$ & $\begin{array}{c}* \# \\
9.33 \pm \\
0.40\end{array}$ \\
\hline $\begin{array}{l}\mathrm{C} S \mathrm{E}+\gamma- \\
\text { radiation(2Gy) }\end{array}$ & $\begin{array}{c}12.76 \pm \\
0.31 \\
\end{array}$ & $\begin{array}{c}3.47 \pm \\
0.27 \\
\end{array}$ & $\begin{array}{c}16.17 \pm \\
0.68 \\
\end{array}$ \\
\hline $\begin{array}{l}\text { Catechin }(50 \mathrm{mg} / \\
\text { k g })+ \text { C S E }+ \\
\gamma \text {-radiation }(2 \mathrm{~Gy})\end{array}$ & $\begin{array}{c}\text { *\#@\$ } \\
7.55 \pm \\
0.38\end{array}$ & $\begin{array}{c}* \$ \\
7.04 \pm \\
0.16\end{array}$ & $\begin{array}{l}\text { @ } \$ \\
12.04 \\
\pm 0.44 \\
\end{array}$ \\
\hline $\begin{array}{l}\text { Rut in ( } 40 \mathrm{mg} / \\
\mathrm{kg})+\end{array}$ & *\#@ @ & $*$ & $* \# \$$ \\
\hline $\begin{array}{l}\text { C S E + }{ }^{-}- \\
\text {radiation(2Gy) }\end{array}$ & $6.56 \pm 0.18$ & $\begin{array}{c}4.37 \pm \\
0.32\end{array}$ & $\begin{array}{c}9.55 \\
\pm 0.49\end{array}$ \\
\hline
\end{tabular}

All values are expressed as mean \pm SE. $(n=8)$

*: significantly different from normal at $\mathrm{p}<0.05$.

\#: significantly different from 2Gy at $\mathrm{p}<0.05$.

@: significantly different from CSE at $\mathrm{p}<0.05$.

$\$$ : significantly different from CSE +2 Gy at $p<0.05$
Effects of catechin or rutin treatment on the activities of serum LDH, mucosal MPO and serum TNF- $\alpha$ level in whole body $\gamma$ - irradiated and CSE treated rats

As shown in Fig. 2, irradiation of rats or administration of CSE induced a significant rise in LDH activity. Furthermore, the MPO activity increased from $1.37 \pm 0.07 \mathrm{U} / \mathrm{g}$ tissue to reach 3.46 $\pm 0.07 \mathrm{U} / \mathrm{g}$ tissue after irradiation and $4.69 \pm 0.22$ $\mathrm{U} / \mathrm{g}$ tissue after CSE administration. Moreover, irradiation led to an increase in TNF- $\alpha$ level from $72.1 \pm 1.94 \mathrm{pg} / \mathrm{ml}$ to $107.7 \pm 2.38 \mathrm{pg} / \mathrm{ml}$ whereas administration of CSE raised its level to 112.8 $\pm 2.2 \mathrm{pg} / \mathrm{ml}$. On the other hand, administration of CSE followed by whole body $\gamma$-irradiation caused more rise in the enzymes activities and TNF- $\alpha$ level. Treatment with catechin or rutin before $\gamma$-radiation and CSE administration resulted in a significant decrease in LDH and MPO activities and TNF- $\alpha$ level.

\section{DISCUSSION}

Exposure of rats to acute dose $2 \mathrm{~Gy}$ of $\gamma$ - radiation induced a significant increase in the activities of serum ALT, AST and ALP. Furthermore, serum LDH was also significantly increased by exposure to 2 Gy $\gamma$-radiation. The increase of ALT and AST is in agreement with the findings of El-Ghazaly and Ramadan (1996) who reported that rats irradiated at 3 or 6 Gy $\gamma$-rays, showed a similar increase in the activities of both enzymes.

The observed increase in alkaline phosphatase activities of $\gamma$-irradiated rats was similar to that of Sharma and Goyal (2005) after irradiation with various doses. Radiation-induced cell death may be a possible reason for the increased activity of ALP (Soyal el al., 2007).In addition, Pradeep el al. (2008) reported that exposure of rats to $\gamma$-radiation at a doses of 1,3 and 5 Gy leads to a marked elevation in the activities of serum AST ALT, ALP, and LDH. This might be due to the release of these enzymes from the cytoplasm into the blood circulation rapidly after rupture of the plasma membrane and cellular damage (Bansal et al., 2000).

Increased levels of MDA (an index of lipid peroxidation), and NO associated with reduced level of GSH were observed in $\gamma$-irradiated rats. These results are in accordance with those of Sener et al. (2006) who found that tissue MDA was increased in the lung, liver, kidney and ileum 
of the whole-body irradiated rats, indicating the presence of radiation-induced oxidative damage. Moreover, the study of Adaramoye (2010) showed an increase of serum levels of MDA, urea and activities of ALT, AST and decrease of GSH level and activities of GST, CAT and SOD in rats exposed to 5 Gy $\gamma$-radiation. The observed increased level of MDA may be due to the attack of free radicals on the fatty acid component of membrane lipids (Kamat et al., 2000), leading to lipid peroxidation.

GSH plays a key role in protecting cells against electrophiles and free radicals (Sies, 1986). Radiation resistance of many cells is associated with high intracellular levels of GSH (Meister, 1991). Cells containing low levels of GSH were found to be much more sensitive to the effect of irradiation than controls (Meister, 1991). GSH can act directly as a free radical scavenger by neutralizing $\mathrm{OH} \bullet$, or indirectly by repairing initial damage to macromolecules inflicted by hydroxyl radical $(\mathrm{OH} \bullet)$ (Sies, 1986). The observed decrease in GSH levels may be due to its consumption during the oxidative stress induced by irradiation (Şener et al., 2006), probably due to an enhanced utilization of the antioxidant system as an attempt to detoxify the free radicals generated by radiation. The decrease in GSH by irradiation could be attributed to oxidation of the sulphydryl group of GSH resulting from the decrease in glutathione reductase and the enzyme which reduces the oxidized glutathione (GSSG) into a reduced form using NADPH (Penney and Roy, 2013).

The present results showed that the whole body $\gamma$-irradiation of rats enhanced the formation of NO. Previous researches were in agreement with our results showing that $\gamma$ - irradiation may enhance endogenous NO biosynthesis in liver, intestine, lung, kidney, brain, spleen or heart of the animals, presumably by facilitating the entry of $\mathrm{Ca} 2+$ ions into the membrane as well as the cytosol of NO-producing cells through irradiation induced membrane lesions (Hong et al., 2013). Conversely, it has been demonstrated that NO donors can ameliorate the intestinal injuries in experimental colitis on the basis that NO might inhibit neutrophil infiltration (an important step in the development of I/R injury) and improve microcirculation resulting from its vasodilatory effect (Muscará and Wallace, 1999).
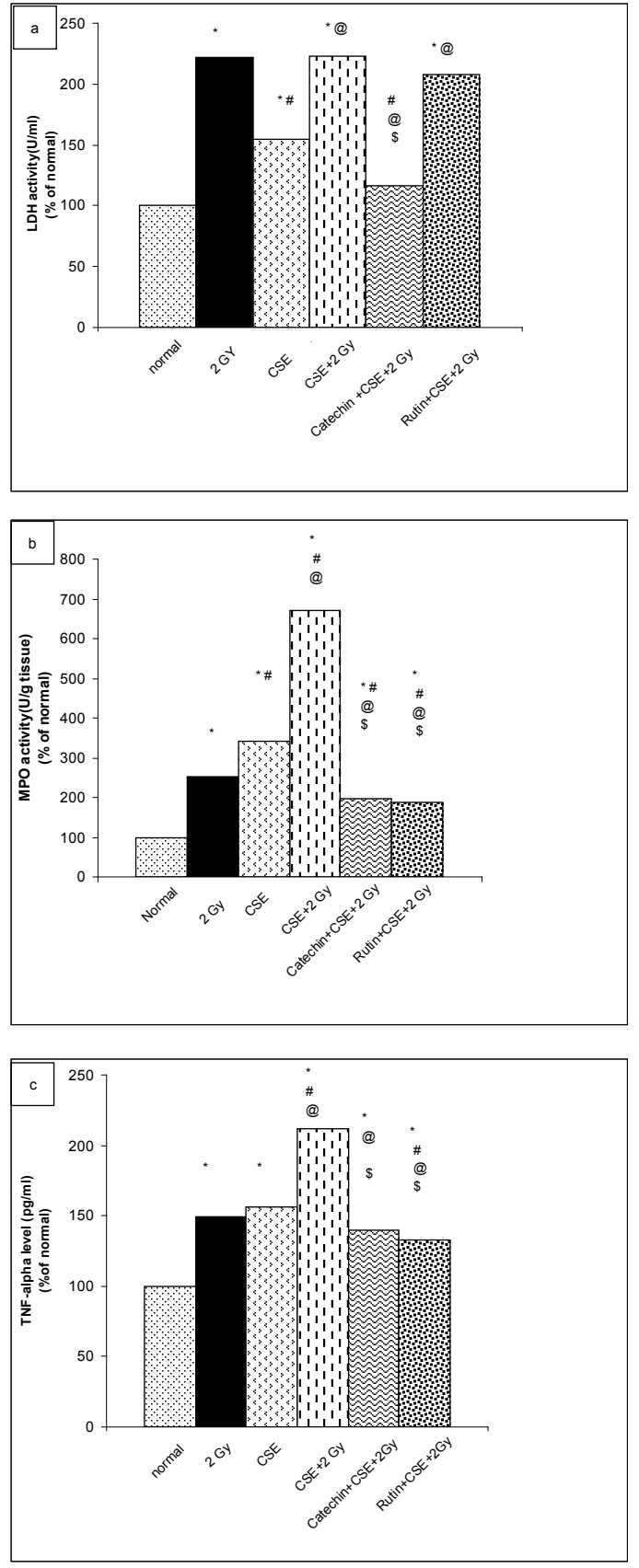

Fig. 2. Effect of catechin $(50 \mathrm{mg} / \mathrm{kg})$ or rutin $(40$ $\mathrm{mg} / \mathrm{kg}$ ) on a) serum activity of lactate dehydrogenase (LDH), (b) mucosal activity of myeloperoxidase (MPO) and (c) serum level of tumor necrosis factor-alpha (TNF- $\alpha$ ) in CSE treated and $\gamma$ - irradiated rats.

.All values are expressed as \% mean .significantly different from normal at $\mathrm{p}<0.05$ :* .significantly different from 2 Gy at $\mathrm{p}<0.05$ :\# .significantly different from CSE at $\mathrm{p}<0.05:$ @ significantly different from CSE +2 Gy at $p<0.05: \$$ 
Elevated MPO activity in the gastric mucosa following the exposure to whole body $\gamma$-radiation, indicated that radiation- induced oxidative injury in the tissue involves the contribution of neutrophil accumulation. The present observation is in agreement with the findings of Miyamoto et al. (2015) who showed that MPO activity in tissue would be increased after whole body irradiation.

Exposure to IR resulted in increased serum TNF- $\alpha$, indicating the role of this cytokine in irradiation-induced toxicity. Tissue damage and repair initiated by irradiation are found to be associated with the production of important biological mediators, including cytokines, which perpetuate the inflammatory and fibrogenic processes associated with irradiation injury (Chen et al., 2015).

A significant elevation in serum AST, ALT and ALP activities was recorded in cigarette smoketreated rats. Similar results have been reported by Pekmez el al. (2007) who observed a significant increase in the activity ofALT, AST, SOD and GSHPx and levels of total bilirubin and MDA in rats exposed to cigarette smoke compared with those of the controls. The damage caused by cigarette smoke is generally associated with free radicals (Ramesh et al., 2010).On the same line, Watanabe et al. (1995) reported a significant decrease in liver weight and increased lipid peroxidation in the liver in cigarette smoke exposed rats. In the smoke treated group, the AST, gamma glutamyl transpeptidase $(\gamma-\mathrm{GTP})$, total bilirubin and LDH values were significantly higher than those in the control group. These results suggested that cigarette smoking might induce liver injury by enhancing lipid peroxidation.

A significant increase in serum MDA level and a decrease in blood GSH level were observed in CSE treated rats. This observation is consistent with the study of Ramesh et al. (2010), who also found a significant increase in MDA and a decrease in GSH in liver and kidney of cigarette smoke exposed rats. Similar results were found in human smokers in the study of Tanriverdi et al. (2006).

The oxidative stress observed in the present study is consistent with earlier reports (Cigremis et al., 2004, Ramesh el al., 2008). Furthermore, Joshi et al. (1988) suggested that depletion of GSH levels by cigarette smoke could be due to either oxidation to GSSG, protein- SSG, conjugation with electrophilic components of cigarette smoke, or markedly inhibited synthesis (Larsson et al., 1983). Moreover, a decreased GSH was reported in the study of Muthukumaran el al. (2008), who suggested that the decreased level of circulation and tissue GSH in nicotine-treated rats may be due to enhanced utilization during detoxification of nicotine.

The present work showed an increase in NO serum level of cigarette smoke treated rats. This finding is in harmony with the study of Wright et al. (1999) who reported an increase in iNOS with CSE. Furthermore, Muthukumaran el al. (2008) also reported an increased level of NO in circulation, lung, liver and kidney of nicotine treated rats. In contrast, a reduction in nitrite levels was reported by Hoyt et al. (2003) together with a reduction in NO synthase (iNOS) mRNA and protein expression after cigarette smoke exposure. The effects of cigarette smoke upon the NO pathways and NOS iso enzymes are controversial and may vary according to the disease, model or location of the NOS. For example, while exhaled NO has been shown to be decreased in humans after acute cigarette exposure, iNOS mRNA expression increased in the lungs of rats exposed to cigarette smoke, while nNOS showed a longer term increase in both transcription and translation (Yates et al., 2001). The effects of cigarette smoke on NOS in the vasculature have shown a reduction in eNOS in the pulmonary vessels in vitro and in vivo (Barbera et al., 2001), while vascular intimal thickening and up-regulated iNOS has been described in mice (Anazawa et al., 2004). These seemingly contradictory effects are probably explained, in part, by the different tissue situations and also by the variation in the constituents of the cigarette smoke (Wei et al., 2005).

There is an increase of MPO activity in gastric mucosa of CSE treated rats reported in the present study which is in agreement with the results of Guo et al. 1999, who found an increase of colonic MPO in rats exposed to CS, suggesting that $\mathrm{CS}$ exposure was able to aggravate neutrophil infiltration and inflammatory damages in the colonic tissue. Cigremis et al. (2006) found that MPO activity was significantly increased in the kidney tissues of CS and ethanol treated rats. Similar alterations in MPO activity have also been reported in other studies such as ethanol 
and cigarette smoke-induced pancreatic injury (Hartwig et al., 2000), and gastric mucosa damage (Arab et al., 2015).

An increase in TNF- $\alpha$ in serum of CSE treated rats was observed which is in line with the results of Petrescu et al. (2010) and Barbieri et al. (2011), who observed elevated levels of TNF- $\alpha$ and IL-1 $\beta$ in the serum of smokers compared with non smokers. In addition, several studies have associated smoking risks with changes in the expression of these cytokines (Hou et al., 2009) emphasizing that short-term exposure to cigarette smoke in vivo is sufficient to increase IL-1 $\beta$ and/ or TNF- $\alpha$ (Barbieri and Weksler, 2007).

Since $\gamma$-irradiation and CSE treatment are considered among the risk factors that induce many cellular injury, their combined effects are expected to be higher than the effects produced by each of them alone. However it seems that previous studies about the effects of their combination are not available.

Treatment with catechin prior to CSE administration and $\gamma$-irradiation in the current study resulted in a significant reduction of liver enzymes activity. These findings are in accordance with the results in the study by Kobayashi et al. (2010) who found that administration of green tea catechin lowered activities of ALT, AST, ALP and $\mathrm{LDH}$ in serum and decreased MDA content in hepatic tissue in rats. Moreover, catechin resulted in less LDH, AST and ALT leakage from cultured hepatocytes, and less morphological alterations by hepatotoxins, suggesting that catechin may act by stabilizing plasma membrane against toxic insults (Uzun and Kalender, 2013).

Administration of rutin prior to CSE treated and $\gamma$-irradiated rats showed a hepatoprotective effects which appear in lowering the liver enzymes activity. This finding is in harmony with the study by Acquaviva et al. (2009) that found that treatment with rutin in rats subjected to I/R injury produced a significant reduction of plasma ALT, AST activities and lipid peroxides level. Rutin is an efficient antioxidant, free radical scavenger and has been shown to quench the hydroxyl radical, superoxide anion radical, and peroxynitrite anion (Patil et al, 2013).

A protective effect of catechin against oxidative stress produced by administration of
CSE and exposure to $\gamma$-irradiation was observed. This could be based on free radical scavenging activity (Chander et al., 2003). Another mechanism by which catechins scavenge free radicals is by forming stable semiquinone free radicals, thus, preventing the deaminating ability of free radicals (Guo et al., 1996).

Our results demonstrated the guarding effect of rutin against oxidative stress caused by $\gamma$-irradiation and CSE administration by decreasing MDA and NO levels and slightly increasing GSH level in rats. Similar results were obtained by Shenbagam and Nalini (2011) who reported that supplementation of rutin along with ethanol significantly decreased the levels of liver marker enzymes, lipidperoxidation and significantly elevated the activities of liver SOD, CAT, GSH, glutathione peroxidase, vitamins $\mathrm{C}$ and $\mathrm{E}$ when compared to untreated ethanol supplemented rats. Rutin possesses a unique ability to inhibit free radical processes in cells at three different stages: an initiation (by the interaction with superoxide ion), the formation of hydroxyl or radicals (by chelating iron ions) and lipid peroxidation (by reacting with lipid peroxy radicals). Lipid peroxidation inhibition is explained by both chelating and antioxidative properties of rutin, as inhibition was observed at flavonoid concentrations much smaller than the concentrations of ferrous ions (Afanas'ev et al., 1989).

The anti-inflammatory action of catechin appeared in the reduction of MPO activity and TNF- $\alpha$ level in rats treated with CSE and irradiated with $\gamma$-rays. The study of Guruvayoorappan and Kuttan, (2008) suggested that (+)-catechin could significantly inhibit nitrite and TNF- $\alpha$ production in lipopolysaccharide (LPS) stimulated macrophages. Khalatbary and Ahmadvand, (2011), reported a significant decrease in MPO activity and attenuation of TNF- $\alpha$, IL- $1 \beta$, and iNOS expression in traumatized spinal cord rats treated with epigallocatechin gallate (EGCG). The anti-inflammatory effects of catechins may be due to their scavenging of $\mathrm{NO}$ and reduction of $\mathrm{NO}$ synthase (NOS) activity (Suzuki et al., 2004).

Results revealed that rutin possesses anti inflammatory potential as reflected by the reduction in the elevated serum TNF- $\alpha$ level and MPO activity of irradiated rats treated with CSE. Rutin was reported to decrease gene expressions and production of the proinflammatory cytokines 
TNF- $\alpha$ and IL-1 $\beta$ levels in stimulated human mast cells (Park et al. 2008). In addition, Abd-ElFattah et al. (2010) reported that supplementation with rutin possesses anti-inflammatory potential as reflected by the reduction in the elevated serum TNF- $\alpha$ and IL- $1 \beta$ levels of irradiated rats subjected to $\mathrm{I} / \mathrm{R}$.

The protective activities of catechin and rutin in the $\gamma$-irradiated and CSE treated animals indicated that, they may have a possible preventive value in the inhibition of tissue damage including oxidative stress and inflammation. Thus, these agents could have the potential to modulate the damage induced by combined $\gamma$-radiation exposure and cigarette smoke.

\section{REFERENCES}

Abd-El-Fattah ,A.A., El-Sawalhi, M.M., Rashed, E.R. and El-Ghazaly, M.A. (2010) Possible role of vitamin E, coenzyme Q10 and rutin in protection against cerebral ischemia/reperfusion injury in irradiated rats. Int. J. Radiat Biol. 86, 1070-1078.

Acquaviva, R., Lanteri ,R., Li Destri, G., Caltabiano, R., Vanella, L., Lanzafame, S. and Di Cataldo A., Li Volti G., Di Giacomo C. (2009) Beneficial effects of rutin and L-arginine coadministration in a rat modelof liver ischemia-reperfusion injury. $\mathrm{Am} \mathrm{J}$ Physiol Gastrointest Liver Physiol. 296, G664G670.

Adaramoye, O.A. (2010) Protective effect of kolaviron, a biflavonoid from Garcinia kola seeds, in brain of Wistar albino rats exposed to gamma radiation. Biol Pharm Bull. 33, 260-266.

Afanas'ev, I.B., Dorozhko, A.I., Brodskii , A.V., Kostyuk, V.A. and Potapovitch, A.I. (1989) Chelating and free radical scavenging mechanisms of inhibitory action of rutin and quercetin in lipid peroxidation. Biochem Pharmacol. 38, 1763- 1769.

Anazawa, T., Dimayuga, P.C., Li, H., Tani, S., Bradfield, J., Chyu, K.Y., Kaul,S., Shah, P.K. and Cercek B. (2004) Effect of exposure to cigarette smoke on carotid artery intimal thickening: the role of inducible NO synthase. Arterioscler Thromb Vasc Biol. 24,1652- 1658.

Arab H.H., Salama S.A., Omar H.A., Arafa E.A. and Maghrabi I.A. (2015) Diosmin Protects against Ethanol-Induced Gastric Injury in Rats: Novel AntiUlcer Actions PLOS ONE 10 (3), 1-21.

Egypt.J.'Rad. Sci. Applic. 39, No.1 (2017)
Babu P.V. and Liu D. (2008) Green tea catechins and cardiovascular health: an update. Curr Med Chem. 15,1840-1850.

Bansal A. K., Trivedi R., Soni G.L., Bhatnagar D. (2000) Hepatic and renal oxidative stress in acute toxicity of Nnitrosodiethylamine in rats. Indian J. of Exp Biol 38, 916-920.

Barbera, J.A., Peinado, V.I., Santos, S., Ramirez, J., Roca, J. and Rodriguez- Roisin, R. (2001). Reduced expression of endothelial nitric oxide synthase in pulmonary arteries of smokers. Am J Respir Crit Care Med. 164, 709-713.

Barbieri, S.S. and Weksler, B.B. (2007) Tobacco smoke cooperates with interleukin-1beta to alter beta-catenin trafficking in vascular endothelium resulting in increased permeability and induction of cyclooxygenase-2 expression in vitro and in vivo. Faseb J. 21, 1831-1843.

Barbieri, S.S., Zacchi, E., Amadio, P., Gianellini, S., Mussoni, L., Weksler, B.B. and Tremoli, E. (2011) Cytokines present in smokers' serum interact with smoke components to enhance endothelial dysfunction. Cardiovasc Res. 90, 475-483.

Belfield, A. and Goldberg, D.M. (1971) Revised assay for serum phenyl phosphatase activity using 4-amino-antipyrine. Enzyme. 12, 561-586.

Beutler, E., Duron, O. and Kelly, B.M. (1963). Improved method for the determination of blood glutathione. $J$. Lab Clin Med. 61, 882-888.

Chander, V., Singh, D. and Chopra, K. (2003) Catechin, a natural antioxidant protects against rabdomyolysisinduced myoglobinuric acute renal failure. Pharmacol Res. 48, 503-509.

Chen, H, Min, X.H., Wang, Q.Y., Leung, F.W., Shi, L., Zhou, Y., Yu, T., Wang, C.M., An, G., Sha, W.H. and Chen Q.K. (2015) Pre-activation of mesenchymal stem cells with TNF-a, IL-1b and nitric oxide enhances its paracrine effects on radiation-induced intestinal injury. Sci. Rep. | 5, 8718.

Cigremis, Y., Turkoz, Y., Akgoz, M. and Sozmen, M. (2004) The effects of chronic exposure to ethanol and cigarette smoke on the level of reduced glutathione and malondialdehyde in rat kidney. Urol Res. 32, 213-218. 
Cigremis, Y., Turkoz, Y., Tuzcu, M., Ozen, H., Kart, A., Gaffaroglu, M., Erdogan, K., Akgoz, M. and Ozugurlu, F. (2006) The effects of chronic exposure to ethanol and cigarette smoke on the formation of peroxynitrite, level of nitric oxide, xanthine oxidase and myeloperoxidase activities in rat kidney. $\mathrm{Mol}$ Cell Biochem. 291, 127-138.

Cook, N.C. and Samman, S. (1996) Flavonoidschemistry, metabolism, cardioprotective effects, and dietary sources. J. Nutr Biochem.7, 66-76.

El-Ghazaly, M.A. and Ramadan, L.A. (1996) Alterations in some metabolic functions in male albino rats after irradiation and possible role of thiola. J. Egypt Soc Toxicol. 16, 105- 109.

Flick, D.A. and Gifford, G.E. (1984) Comparison of in vitro cell cytotoxic assays for tumor necrosis factor. J. Immunol Methods. 68,167-175.

Florek, E., Ignatowicz, E., Wrzosek, J. and Piekoszewski W. (2005) Effect of rutin on total antioxidant status of rats exposed to cigarette smoke. Pharmacol Rep. 57, 84-89.

Gay, R.J., McComb, R.B. and Bowers, G.N. Jr. (1968) Optimum reaction conditions for human lactate dehydrogenase isoenzyme as they affect total lactate dehydrogenase activity. Clin Chem. 14, 740-753.

Guo, Q., Zhao, B., Li, M., Shen, S. and Xin, W. (1996) Studies on protective mechanisms of four components of green tea polyphenols against lipid peroxidation in synaptosomes. Biochim Biophys Acta. 1304, 210- 222.

Guo, X., Wang, W.P., Ko, J.K. and Cho, C.H. (1999) Involvement of neutrophils and free radicals in the potentiating effects of passive cigarette smoking on inflammatory bowel disease in rats. Gastroenterology. 117, 884-892.

Guruvayoorappan, C. and Kuttan, G. (2008) (+)Catechin inhibits tumour angiogenesis and regulates the production of nitric oxide and TNF-alpha in LPS-stimulated macrophages. Innate Immun. 14,160- 174.

Hartwig, W., Werner, J., Ryschich, E., Mayer, H., Schmidt, J., Gebhard, M.M., Herfarth, C. and Klar, E. (2000) Cigarette smoke enhances ethanolinduced pancreatic injury. Pancreas. 21, 272-278.

Hauer-Jensen, M., Wang, J., Boerma, M., Fu, Q. and
Denham, J.W. (2007) Radiation damage to the gastrointestinal tract: mechanisms, diagnosis, and management. Curr Opin Support Palliat Care. 1, 23-29.

Hong, C.W., Kim, Y.M., Pyo, H., Lee, J.H., Kim, S., Lee, S. and Noh, J.M. (2013) Involvement of inducible nitric oxide synthase in radiation-induced vascular endothelial damage. J. Radiat Res 54 (6), 1036-1042.

Hou, L., Huang, J., Lu, X., Wang, L., Fan, Z. and Gu, D. (2009) Polymorphisms of tumor necrosis factor alpha gene and coronary heart disease in a Chinese Han population: interaction with cigarette smoking. Thromb Res. 123, 822-826.

Hoyt, J.C., Robbins, R.A., Habib, M., Springall, D.R., Buttery, L.D., Polak, J.M. and Barnes, P.J. (2003) Cigarette smoke decreases inducible nitric oxide synthase in lung epithelial cells. Exp Lung Res. 29, $17-28$.

Joshi,U.M., Kodavanti,P.R. and Mehendale,H.M.(1988) Glutathione metabolism and utilization of external thiols by cigarette smoke challenged, isolated rat and rabbit lungs. Toxicol Appl Pharmacol. 96,324-335.

Kamat, J.P., Boloor, K.K., Devasagayam, T.P. and Venkatachalam, S.R. (2000) Antioxidant properties of Asparaguss racemous against damage induced by -radiation in rat liver mitochondria. J. Ethnopharmacol. 71, 425-435.

Khalatbary, A.R. and Ahmadvand, H. (2011) Antiinflammatory effect of the epigallocatechin gallate following spinal cord trauma in rat. Iran Biomed $J$. 15, 31- 37 .

Kobayashi, H., Tanaka, Y., Asagiri, K., Asakawa ,T., Tanikawa, K., Kage, M. and Yagi, M. (2010) The antioxidant effect of green tea catechin ameliorates experimental liver injury. Phytomedicine. 17, 197 202.

Larsson, A., Orrenius, S., Holmgren, A. and Mannervik, B. (1983) Functions of Gluthatione: Biochemical, Physiological, Toxicological and Clinical Aspects. Raven Press, New York.

Lindahl, M. and Tagesson, C. (1997) Flavonoids as phospholipase A2 inhibitors: importance of their structure for selective inhibition of group II phospholipase A2. Inflammation. 21, 347-356.

Egypt.J.Rad. Sci. Applic. 39, No.1 (2017) 
Ma, L., Chow, J.Y.C. and Cho, C.H. (1999) Cigarette smoking delays ulcer healing: role of constitutive nitric oxide synthase in rat stomach. Am J. Physiol. 276, G238-G248.

Ma, L., Wang, W.P., Chow, J.Y., Lam, S.K. and Cho, C.H. (2000) The role of polyamines in gastric mucus synthesis inhibited by cigarette smoke or its extract. Gut. 47,170-177.

Meister, A. (1991) Glutathione deficiency produced by inhibition of its synthesis, and its reversal; applications in research and therapy. Pharmacol Ther. 51,155-194.

Meister, M. (2005) The Health Effects of Low-Level Radiation. American council on Science and Health, New York, pp. 2-4.

Metodiewa, D., Kochman, A. and Karolczak, S. (1997) Evidence for antiradical and antioxidant properties of four biologically active $\mathrm{N}, \mathrm{N}$ diethylaminoethyl ethers of flavanone oximes: a comparison with natural polyphenolic flavonoid (rutin) action. Biochem Mol Biol Int. 41, 1067-1075.

Miyamoto, H., Kanayama, T., Horii, K., Kawai, T., Tsuchimochi, T., Shigetomi, T., Shibamoto, Y. and Shibuya, Y. (2015) The relationship between the severity of radiation-induced oral mucositis and the myeloperoxidase levels in rats. Oral Surg, Oral Med, Oral Pathol and Oral Radiol 120 (3), 329-336

Montgomery, H.A.C. and Dymock, J.F. (1961) The determination of nitrite in water. Analyst. 86, 414-416.

Muscará, M.N. and Wallace, J.L. (1999) Nitric Oxide. V. therapeutic potential of nitric oxide donors and inhibitors. Am J Physiol. 276, 1313-6.

Muthukumaran, S., Sudheer, A.R., Menon, V.P. and Nalini, N. (2008) Protective effect of quercetin on nicotine-induced prooxidant and antioxidant imbalance and DNA damage in Wistar rats. Toxicology. 243, 207-215.

Park, H.H., Lee, S., Son, H.Y., Park, S.B., Kim, M.S., Choi, E.J., Singh, T.S., Ha, J.H., Lee, M.G., Kim ,J.E., Hyun, M.C., Kwon, T.K., Kim, Y.H. and Kim, S.H. (2008) Flavonoids inhibit histamine release and expression of proinflammatory cytokines in mast cells. Archives of Pharmacal Research. 31,1303-1311.

Patil, S.L., Mallaiah, S.H. and Patil, R.K. (2013) Antioxidative and radioprotective potential of rutin and quercetin in Swiss albino mice exposed to gamma radiation. J. Med Phys. 38 (2), 87-92.

Pekmez, H., Kus, I., Colakoglu, N., Ogeturk, M., Ozyurt, H., Turkoglu, A.O. and Sarsilmaz, M. (2007) The protective effects of caffeic acid phenethyl ester (CAPE) against liver damage induced by cigarette smoke inhalation in rats. Cell Biochem Funct. 25, 395-400.

Penney, R.B., and Roy, D. (2013) Thioredoxin-mediatedredoxregulationof resistancetoendocrinetherapyinbreastcancer. Biochim.Biophys. Acta 1836, 60-79

Pérez Guerrero, C., Martín, M.J. and Marhuenda, E. (1994) Prevention by rutin of gastric lesions induced by ethanol in rats: role of prostaglandins. Gen Pharmacol. 25, 575-580.

Petrescu, F., Voican, S.C. and Silosi, I. (2010) Tumor necrosis factor-alpha serum levels in healthy smokers and nonsmokers. Int J. Chron Obstruct Pulmon Dis.

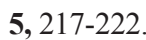

Pradeep, K., Park, S.H. and Ko, K.C. (2008) Hesperidin a flavanoglycone protects against $\gamma$-irradiation induced hepatocellular damage and oxidative stress in Sprague-Dawley rats. Eur. J. Pharmacol. 587, 273-280.

Ramesh, T., Mahesh, R., Sureka, C. and Begum, V.H. (2008) Cardioprotective effects of Sesbania grandiflora in cigarette smoke-exposed rats. $J$. Cardiovasc Pharmacol., 52, 338-343.

Ramesh, T., Sureka, C., Bhuvana, S. and Hazeena, Begum V. (2010) Sesbania grandiflora diminishes oxidative stress and ameliorates antioxidant capacity in liver and kidney of rats exposed to cigarette smoke. J. Physiol Pharmacol., 61, 467-476.

Rao, ChV. and Vijayakumar, M. (2007) Protective effect of $(+)$-catechin against gastric mucosal injury induced by ischaemia-reperfusion in rats. rat liver during hypoxia. Am J. Physiol. 258, G499-G505.

Reitman, S. and Frankel, S. (1957) A colorimetric method for the determination of serum glutamic oxalacetic and glutamic pyruvic transaminases. $\mathrm{Am}$ J. Clin Path. 28, 56-63.

Rubin, P., Finkelstein, J. and Shapiro, D. (1992) Molecular biology mechanisms in the radiation induction of pulmonary injury syndromes: interrelationship between the alveolar macrophage and the septal fibroblast. Int J. Radiat Oncol Biol Phys. 24, 93-101 
Sallie, R., Tredger, J.M. and Willam, R. (1991) Drugs and the liver. Biopharm Drug Dispos. 12, 251-259.

Sharma, A. and Goyal, P.K. (2005) Radioprotective capacity of Emblica officinalis against radiation induced biochemical alterations in liver of Swiss albino mice. J. Cell Tissue Res., 51, 341-344

Shenbagam M. and Nalini N. (2011) Dose response effect of rutin a dietary antioxidant on alcoholinduced prooxidant and antioxidant imbalance - a histopathologic study. Fundam Clin Pharmacol., 25, 493-502.

Sies, H. (1986) Biochemistry of oxidative stress. Angewandte Chemie. 285, 37092-37101.

Soyal, D., Jindal, A., Singh, I. and Goyal, PK. (2007) Modulation of radiationinduced biochemical alterations in mice by rosemary (Rosemarinus officinalis) extract. Phytomedicine. 14, 701-705.

Suzuki, M., Tabuchi, M., Ikeda, M, Umegaki, K. and Tomita, T. (2004) Protective effects of green tea catechins on cerebral ischemic damage. Med Sci Monit. 10: BR166- BR174.

Tanriverdi, H., Evrengul, H., Kuru, O., Tanriverdi, S., Seleci, D., Enli, Y., Kaftan, H.A. and Kiliç, M. (2006) Cigarette smoking induced oxidative stress may impair endothelial function and coronary blood flow in angiographically normal coronary arteries. Circ J. 70, 593-599.
Tsiara, S., Elisaf, M. and Mikhailidis, D.P. (2003) Influence of smoking on predictors of vascular disease. Angiology. 54, 507-530.

Uchiyama, M. and Mihara, M. (1978) Determination of malonaldehyde precursor in tissues by thiobarbituric acid test. Anal. Biochem. 86, 271- 278.

Uzun, F.G. and Kalender, Y. (2013) Chlorpyrifos induced hepatotoxic and hematologic changes in rats: the role of quercetin and catechin. Food Chem Toxicol. 55, 549-56.

Watanabe, K., Eto, K., Furuno, K., Mori, T., Kawasaki H., Gomita Y. (1995) Effect of cigarette smoke on lipid peroxidation and liver function tests in rats. Acta Med Okayama. 49, 271-274.

Wei, X.M., Kim, H.S., Kumar, R.K., Heywood, G.J., Hunt, J.E., McNeil, H.P. and Thomas, P.S. (2005) Effects of cigarette smoke on degranulation and NO production by mast cells and epithelial cells. Respir Res. 6, 108-116.

Wright, J.L., Dai, J., Zay, K., Price, K., Gilks, C.B. and Churg, A. (1999) Effects of cigarette smoke on nitric oxide synthase expression in the rat lung. Lab Invest. 79, 975-983.

Yates, D.H., Breen, H. and Thomas, P.S. (2010) Passive smoke inhalation decreases exhaled nitric oxide in normal subjects. Am J Respir Crit Care Med. 164, 1043-1046.

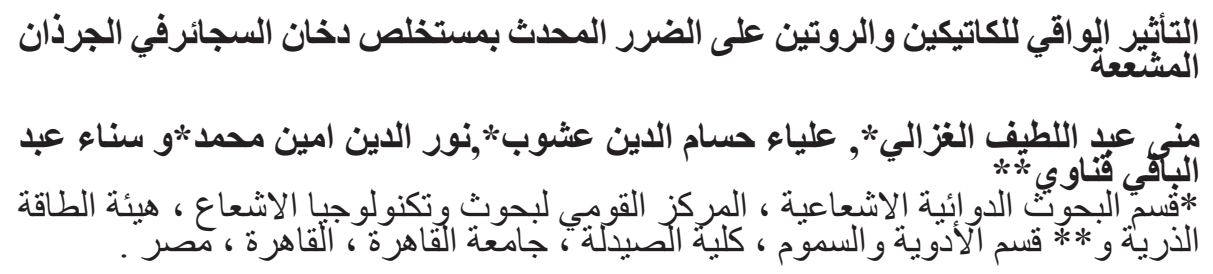

تم في هذا البحث دراسة تأثيربعض مضادات الأكسدة (كاتيكين وروتين) في بعض التغيرات نتيجة تعرض ذإن ذكور الجرذان

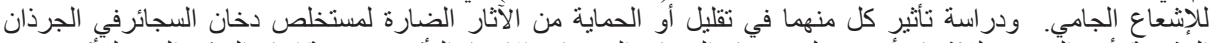

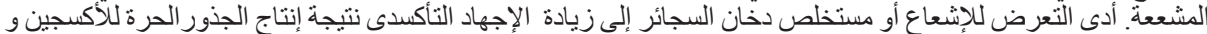

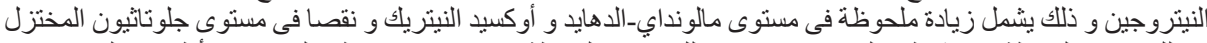

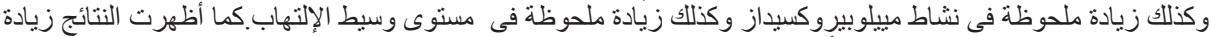

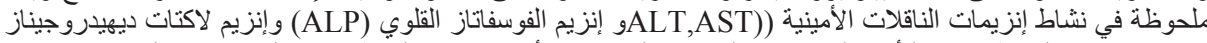

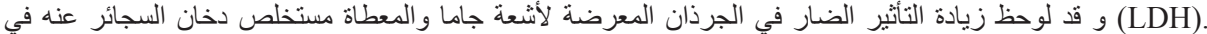

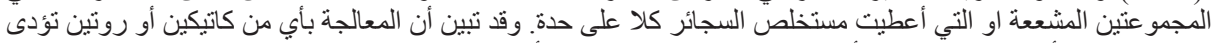

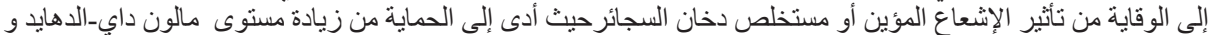

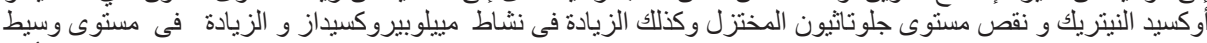

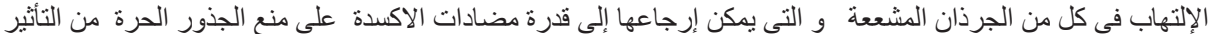

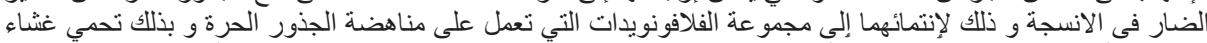

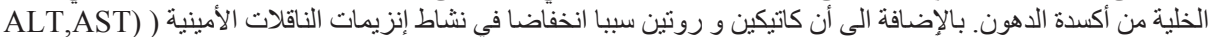

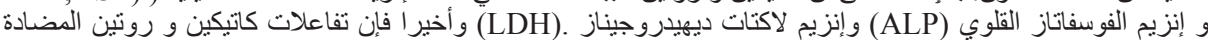
للإلتهاب و قدرنهما على تقليل الإجهاد التأكسدي يوضح قيمنهما المحتملة في منع تلف الأنسجة نتيجة تفاعلات الجذان التهر الحرة. 
Egypt.J.Rad. Sci. Applic. 39, No.1 (2017) 